\title{
Expectations of Emergency Residents and Faculty Members from Each Other: A Turkish Survey
}

\author{
Yunus Emre Arik (D), Ayhan Ozhasenekler ${ }^{2}$ (D) Gul Pamukcu Gunaydin³ (D), Alp Sener ${ }^{3}$, Fatih Tanriverdi² (D), Gulhan Kurtoglu Celik² (D), \\ Mehmet Ergin² (iD, Servan Gokhan² (iD \\ 'Department of Emergency Medicine, Sisli Hamidiye Etfal Training and Research Hospital, Istanbul, Turkey \\ 2Department of Emergency Medicine, Yildirim Beyazit University, Ankara, Turkey \\ ${ }^{3}$ Department of Emergency Medicine, Ankara Ataturk Training and Research Hospital, Ankara, Turkey
}

Cite this article as: Arik YE, Ozhasenekler A, Pamukcu Gunaydin G, Sener A, Tanriverdi F, Kurtoglu Celik G, et al. Expectations of Emergency Residents and Faculty Members from Each Other: A Turkish Survey. Eurasian J Emerg Med. 2018; $17:$ 59-64.

\begin{abstract}
Aim: The objective of the present study was to define the expectations of the residents and faculty members from each other in the process of emergency medicine (EM) residency training.

Materials and Methods: This is a descriptive and cross-sectional study of residents and faculty members who were affiliated with emergency departments throughout Turkey. The study was performed using a questionnaire including 50 questions. The first 9 questions were about demographic information, questions 10-17 were about the program's training characteristics, questions 18-31 were about the faculty's training competence, and questions 32-49 were about the faculty members' personal and social features. Questions 10-49 were Likert scale questions, and the last question (50) was open-ended.

Results: Overall, 93 (24.2\%) of the included participants were EM faculty members, whereas 291 (75.8\%) were EM residents. There were significant differences between faculty members and residents in almost all questions. The three most common expectations of EM residents were "education/training should be more important than patient care," "increasing practical training hours," and "increasing bedside teaching." On the other hand, the most common expectations of the faculty members were "being more enthusiastic to learn" and "more scientific literature reading."

Conclusion: Our results suggest that faculty members and residents have different expectations. In general, faculty members tended to view the program and themselves better than residents' views.
\end{abstract}

Keywords: Emergency medicine residency, emergency medicine faculty, graduate medical education

\section{Introduction}

Owing to the fact that it is a relatively young discipline as in other countries, efforts for the standardization and improvement of emergency medicine (EM) education have been continuing in Turkey (1-6). Despite having a standard curriculum, the applicability of this standard training program is a matter of debate, owing to the intensity of patient load (6).
To increase the quality of training, it is quite important to define the expectations of EM residents during residency. Although there are continuous efforts to establish EM education/training programs and improve curricula (1-6), there are limited studies on the subject, and the available data are insufficient.

The objective of the present study was to define the expectations of the residents and faculty members for the process of EM residency training and evaluate this training from the view of faculty members and residents.

ORCID IDs of the authors: Y.E.A. 0000-0002-4521-9546; A.O. 0000-0002-2707-4099; G.P.G. 0000-0001-8531-4591; A.S. 0000-0002-05832936; F.T. 0000-0001-9959-5769; G.K.C. 0000-0003-1259-3694; M.E. 0000-0002-9420-6514; S.G. 0000-0002-1758-3383. 


\section{Materials and Methods}

\section{Study design and setting}

This multicenter, descriptive, cross-sectional study of EM residents and faculty members at EM residency programs in Turkey was conducted between October 15, 2015 and January 15, 2016. All of these programs in Turkey are 4-year programs. The study protocol was approved by the institutional review board of Yıldırım Beyazıt University before the start of the study.

\section{Selection of participants}

All residents and faculty members who were affiliated with the EM residency programs of university hospitals or training and research hospitals run by the Ministry of Health in different cities in Turkey during the study period were included. Participation was voluntary. Informed consent was obtained through electronic questionnaires.

Subjects who refused to fill out the questionnaire and those who could not be contacted by e-mail were excluded. Participants who did not respond to all questions were also excluded.

\section{Survey implementation}

E-mails of the participants were obtained from the two EM associations in Turkey (Emergency Medicine Physicians Association of Turkey and Emergency Medicine Association of Turkey). Data were collected by an online questionnaire using Google Forms, which is an online survey creation and distribution program (https://docs.google. $\mathrm{com} /$ forms $/ \mathrm{u} / 0 /$ ). Anonymous questionnaires were distributed to EM residents and faculty by e-mail. Questionaires were included in the study if filled during the 3-month study period.
A cover letter about the study and the questionnaire was delivered at the same time to participants via e-mail. E-mail communications were not personalized. With the inclusion of the initial notice, participants were contacted up to five times with reminder notifications to fill out the questionnaire.

\section{The Questionnaire}

The survey was piloted by five EM residents and five EM faculty members and revised before distribution. The final questionnaire comprised 50 items. The first 9 questions were about demographic information, questions 10-17 were about the program's training characteristics, questions 18-31 were about the faculty's training competence, and questions 32-49 were about the faculty members' personal and social features. Questions 10-49 were Likert scale questions, and the last question (50) was an open-ended question about the expectations of trainers and residents.

Table 1 shows the questionnaire distributed to the residents and faculty members. Participants rated their answers using a 5-point Likert-type response scale (1, strongly disagree; 2, disagree; 3, undecided; 4, agree; and 5, strongly agree).

\section{Statistical analysis}

Statistical analysis was performed using Statistical Package for the Social Science version 15.0 (SPSS Inc.; Chicago, IL, USA). Frequency distributions for categorical variables and descriptive statistics for continuous variables were measured. The Kolmogorov-Smirnov test was used to evaluate whether a parameter has normal distribution. The Mann-Whitney $U$ test was used to compare the median between the independent groups. Independent

Table 1. Program's training characteristics (questions 10-17)

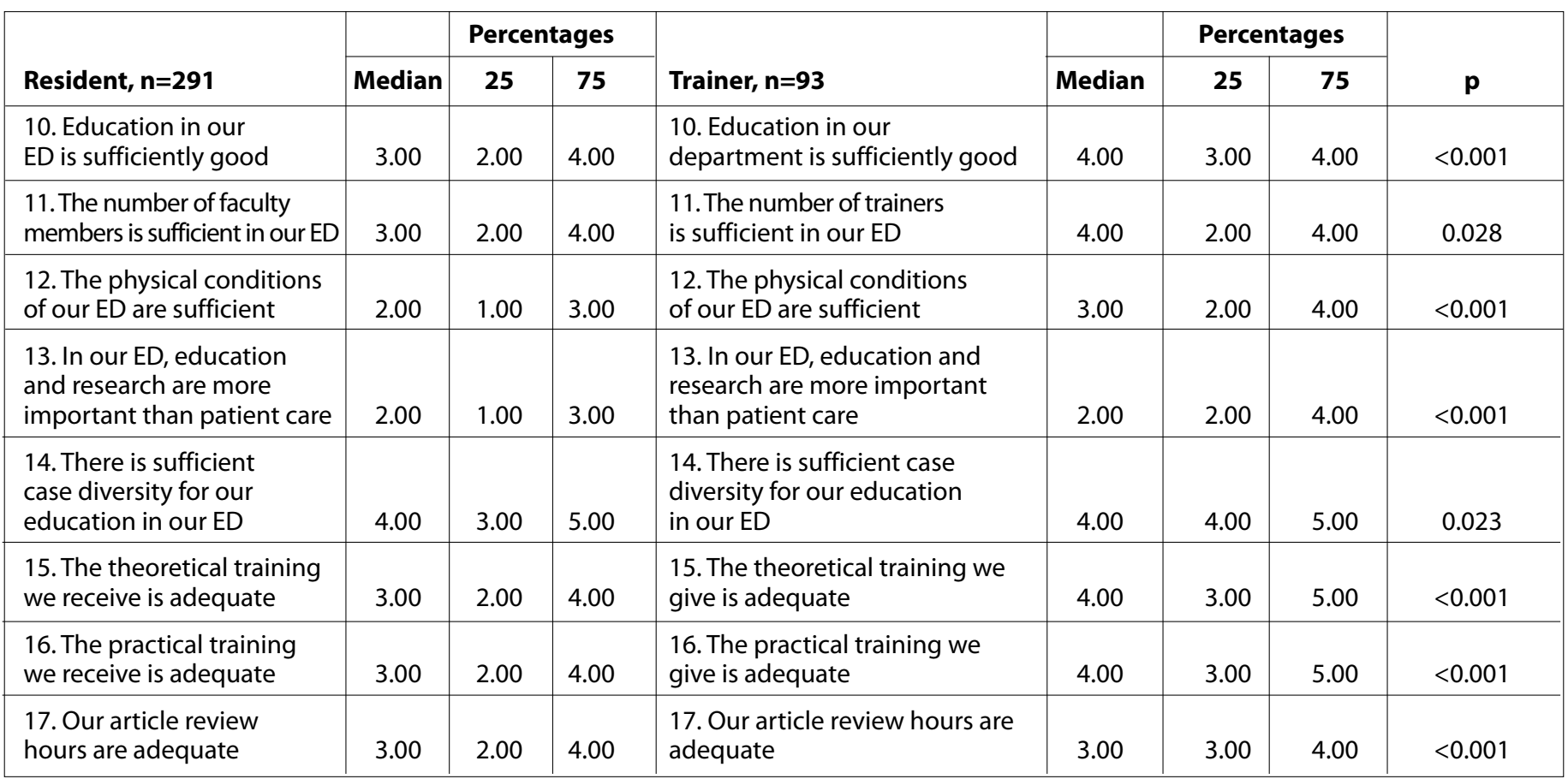

ED: emergency department 
dichotomous data were evaluated using the chi-square test. The Kruskal-Wallis test and Bonferroni correction were used to compare the median of multiple groups. A $p$ value $<0.05$ was considered statistically significant.

\section{Results}

The questionnaire was emailed to 1180 subjects. These e-mails belonged to 928 EM residents and 252 faculty members. Overall, 402 subjects responded to the survey and were included in the study. The overall response rate was 34\%. Of the 402 subjects, $384(95.5 \%)$ responded to all questions and were included in the statistical analysis.

In total, $93(24.2 \%)$ of the total participants were emergency department (ED) faculty members, whereas 291 (75.8\%) were ED residents. Overall, $262(68.2 \%)$ of the participants were men. Of the total participants, 206 (53.6\%) were working in university hospitals, and $178(46.4 \%)$ were working in training and research hospitals.

Tables 1-3 summarize the questions and answers. Tables 4 and 5 show the expectations of the residents and faculty members. There were significant differences between the answers of residents and trainers in all categories (program's training characteristics, faculty's training competence, and faculty members' personal and social features).

\section{Discussion}

In the present study, we aimed to determine the views and expectations of EM residents and faculty members about their EM residency program and each other. In our study, the faculty's self-

Table 2. Faculty's training competence (questions 18-31)

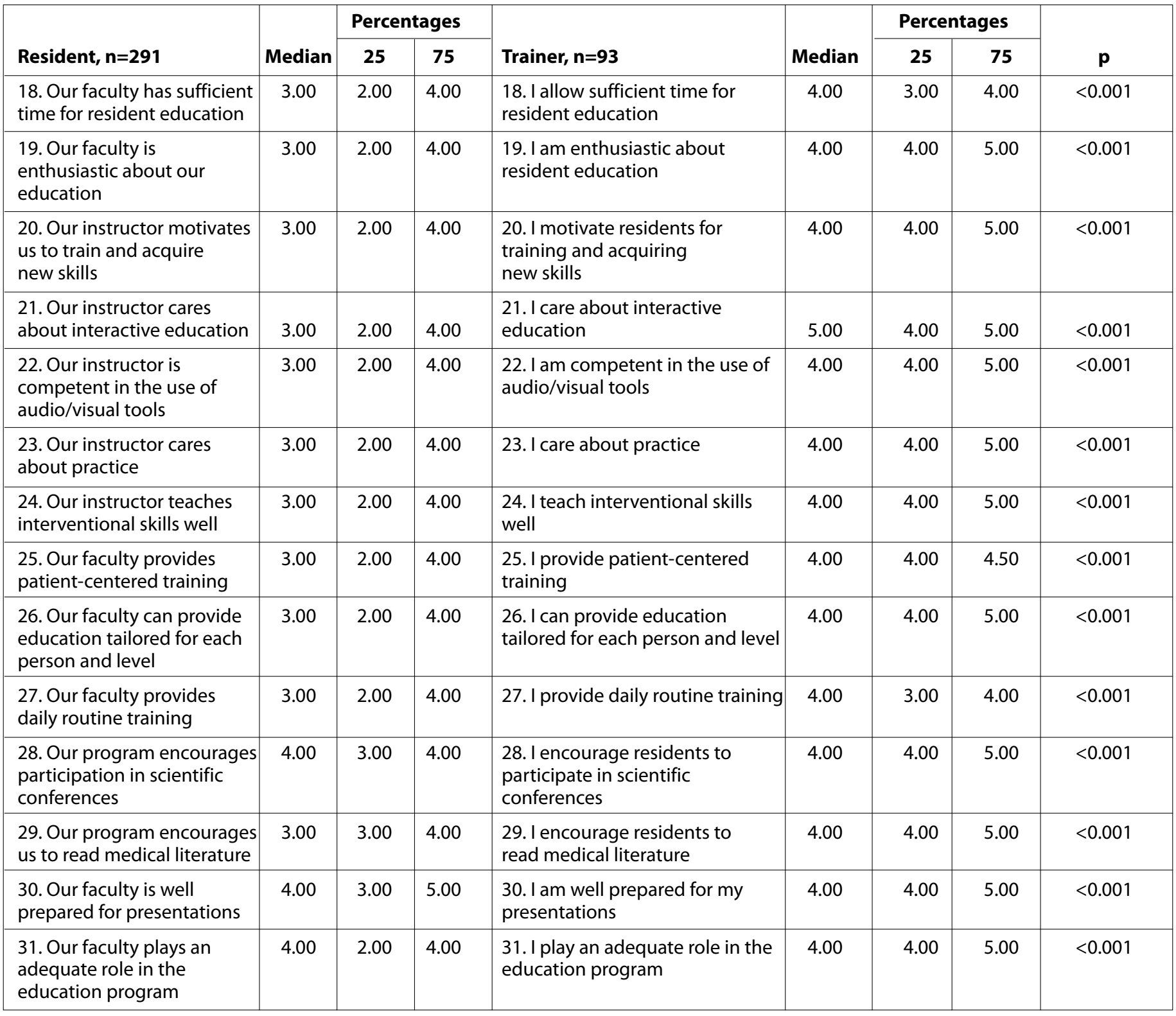

ED: emergency department 
view of competence and the residents' view of faculty performance did not match. The reasons for this discrepancy and its effects on residency training are subjects for future research.

EDs have many opportunities and case diversity for education (7). Moreover, an ED was previously reported to be an ideal environment for bedside teaching, owing to several advantages such as high patient volume, increased acuity of illness, and variety of pathologies (8). Tan et al. (9) reported that approximately three-quarters of the internal branch residents and surgical branch residents are satisfied with the variety of cases. In our study, both residents and faculty members were satisfied with patient variety but found the patient volume to be high.

The conditions of the work and physical environment are one of the major obstacles in ED resident training. Tan et al. (9) stated that although the residents of the basic medicine departments believe that the physical conditions are good, the residents of the internal and surgical departments state that the physical conditions are insufficient. In our study, it turned out that the ED residents also did not find the physical conditions satisfactory, whereas the EM faculty members found them to be sufficient. We believe that improving

Table 3. Faculty's personal and social features (questions 32-49)

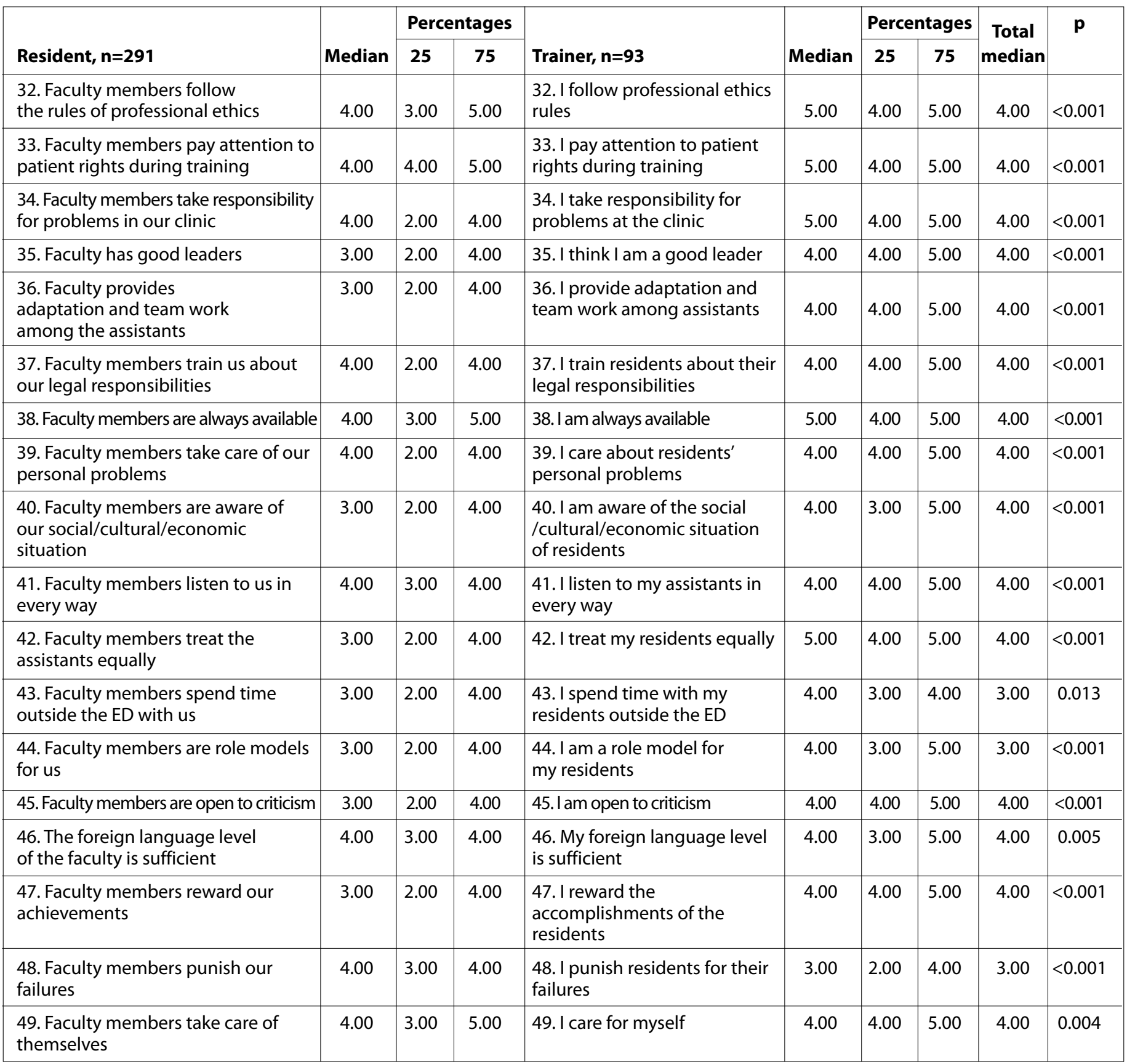


Table 4. Expectations of the residents from faculty and residency training

\begin{tabular}{|l|c|}
\hline Answers/expectations & $\mathbf{n}(\%)$ \\
\hline $\begin{array}{l}\text { Education/training should be more important than } \\
\text { healthcare delivery to higher number of patients }\end{array}$ & $18(17.1)$ \\
\hline Practical training hours should be increased & $14(13.3)$ \\
\hline Bedside teaching hours should be increased & $14(33.3)$ \\
\hline Weekly working hours should be reduced & $10(9.5)$ \\
\hline $\begin{array}{l}\text { Physical conditions of department should be } \\
\text { improved }\end{array}$ & $9(8.5)$ \\
\hline $\begin{array}{l}\text { To see less number of non-urgent patients during } \\
\text { training }\end{array}$ & $9(8.5)$ \\
\hline $\begin{array}{l}\text { Patient admission procedures to inpatient beds } \\
\text { should be accelerated }\end{array}$ & $7(6.6)$ \\
\hline Medical literature review hours should be increased & $6(5.7)$ \\
\hline Faculty members should be more active in training & $6(5.7)$ \\
\hline
\end{tabular}

Table 5. Expectations of the faculty members from their residents

\begin{tabular}{|l|c|}
\hline Answers/expectations & $\mathbf{n}(\%)$ \\
\hline Being more enthusiastic and willing to learn & $18(38.2)$ \\
\hline To read more medical literature articles & $18(38.2)$ \\
\hline $\begin{array}{l}\text { Loving emergency medicine and willingly choose } \\
\text { this residency }\end{array}$ & $8(17.0)$ \\
\hline Being ethical & $7(14.8)$ \\
\hline Being inquisitive & $6(12.7)$ \\
\hline Being respectful & $6(12.7)$ \\
\hline Being responsible & $6(12.7)$ \\
\hline Increasing article review hours & $5(10.6)$ \\
\hline Being more socially involved in department activities & $3(6.3)$ \\
\hline
\end{tabular}

the working conditions and the physical environment would make a positive contribution to ED resident education.

Under the difficult environments of EDs, dedicating sufficient time for education requires work. The trainers should search for opportunities for education despite the constant intensity of emergency services (10). In the study by Thurgur et al. (11), ED residents were asked about their expectations from the faculty. One of the most popular answers was that sufficient time should be dedicated to training, and these hours need to be better spent. In our study, residents also thought both theoretical and practical training is not sufficient.

Tan et al. (9) found that residents in the basic medical sciences and internal medical sciences stated that "education/training is more frontline than service delivery in their services" whereas residents in the surgical departments answered contrary. In our results, "education/ training should be more front-line than patient service delivery" was the most popular expectation of residents. This may be due to the high number of patients being taken care of everyday in EDs in Turkey.
When the EM trainers were asked about their expectations from residents, the two most popular responses were "being enthusiastic and willing to learn" and "literature review and reading." These two answers were compatible with those in previous similar studies (11, 12). In this regard, we believe that ED trainers need to lead their residents. Other popular answers from our participants were "loving emergency medicine and willingly choose this department," "being ethical," and "questioning." Tan et al. (9) found that occupational satisfaction was higher among residents who voluntarily selected their departments to work.

\section{Study limitations}

The present study has some limitations. Because our study was conducted only among EM residency programs in Turkey, the results cannot be generalized to other countries where physical conditions, expectations, and working hours might be different. Residents who were most dissatisfied with their education may be more likely to respond than those who were completely satisfied. We did not analyze the distribution of how many responses came from which programs, and this may have resulted in selection bias. The response rates were insufficient. We were unable to match residents and faculty members from the same programs. Thus, we could not analyze if most answers from residents who are dissatisfied were from the same programs.

\section{Conclusion}

Our results suggest that faculty members and ED residents have different expectations. In the light of our results, we can conclude that "education/training should be more front-line than service delivery," "increasing practical training hours," and "increasing bedside teaching" are the most common expectations of ED residents. On the other hand, "being more enthusiastic and willing" and "following the literature" are the most common expectations of trainers. We believe that ED educators and administrators should take the results of our study into consideration in order to meet the expectations and improve the quality of ED education.

Ethics Committee Approval: Ethics committee approval was received for this study from the ethics committee of Yildirim Beyazit University Faculty of Medicine (Date: 21.10.2015/Number: 222).

Informed Consent: Informed consent was obtained through electronic questionnaires.

Peer-review: Externally peer-reviewed.

Author Contributions: Concept - Y.E.A., A.O., G.P.G., A.S., F.T., G.K.C., M.E., S.G.; Design - Y.E.A., A.O., G.P.G., A.S., F.T., G.K.C., M.E., S.G.; Supervision - Y.E.A., A.O., G.P.G., A.S., F.T., G.K.C., M.E., S.G.; Resources - Y.E.A., A.O., G.P.G., A.S., F.T., G.K.C., M.E., S.G.; Materials - Y.E.A., A.O., G.P.G., A.S., F.T., G.K.C., M.E., S.G.; Data Collection and/or Processing - Y.E.A., A.O., G.P.G., A.S., F.T., G.K.C., M.E., S.G.; Analysis and/or Interpretation - Y.E.A., A.O., G.P.G., A.S., F.T., G.K.C., M.E., S.G.; Literature Search - Y.E.A., A.O., G.P.G., A.S., F.T., G.K.C., M.E., S.G.; Writing Manuscript - Y.E.A., A.O., G.P.G., A.S., F.T., G.K.C., M.E., S.G.; Critical Review Y.E.A., A.O., G.P.G., A.S., F.T., G.K.C., M.E., S.G.; Other - Y.E.A., A.O., G.P.G., A.S., F.T., G.K.C., M.E., S.G.

Conflict of Interest: The authors have no conflict of interest to declare.

Financial Disclosure: The authors declared that this study has received no financial support. 


\section{References}

1. Hosein Nejad H, Bagherabadi M, Sistani A, Dargahi H. Effectiveness of resident as teacher curriculum in preparing emergency medicine residents for their teaching role. J Adv Med Educ Prof. 2017; 5: 21-5.

2. Greenstein J, Hardy R, Chacko J, Husain A. Demographics and Fellowship Training of Residency Leadership in EM: A Descriptive Analysis. West $J$ Emerg Med. 2017; 18: 129-32. [CrossRef]

3. Lee S, Jordan J, Hern HG, Kessler C, Promes S, Krzyzaniak S, et al. Transition of Care Practices from Emergency Department to Inpatient: Survey Data and Development of Algorithm. West J Emerg Med. 2017; 18: 86-92. [CrossRef]

4. Bentley S, Hu K, Messman A, Moadel T, Khandelwal S, Streich H, et al. Are All Competencies Equal in the Eyes of Residents? A Multicenter Study of Emergency Medicine Residents' Interest in Feedback. West J Emerg Med. 2017; 18: 76-81. [CrossRef]

5. Ketterer AR, Salzman DH, Branzetti JB, Gisondi MA. Supplemental Milestones for Emergency Medicine Residency Programs: A Validation Study. West J Emerg Med. 2017; 18: 69-75. [CrossRef]
6. London KS, Druck J, Silver M, Finefrock D. Teaching the Emergency Department Patient Experience: Needs Assessment from the CORD-EM Task Force. West J Emerg Med. 2017; 18: 56-9. [CrossRef]

7. Duong DK, Choo EK, Tabas JA. Obstacles inherent in the emergency department. In: Rogers RL, Mattu A, Winters ME, Martinez JP, Mulligan TM editors. Practical teaching in emergency medicine. West sussex: John Wiley \& Sons, Ltd., 2013, p. 15.

8. Aldeen AZ, Gisondi MA. Bedside teaching in the emergency department. Acad Emerg Med. 2006; 13: 860-6. [CrossRef]

9. Tan MN, Özçakar N, Kartal M. Resident Doctors' Professional Satisfaction and Its Effect on Their Lives. Marmara Med J. 2012; 25: 20-5.

10. Atzema C, Bandiera G, Schull MJ. Emergency department crowding: the effect on resident education. Ann Emerg Med. 2005; 45: 276-81. [CrossRef]

11. Thurgur $L$, Bandiera $G$, Lee $S$, Tiberius $R$. What do emergency medicine learners want from their teachers? A multicenter focus group analysis. Acad Emerg Med. 2005; 12: 856-61. [CrossRef]

12. Sutkin G, Wagner E, Harris I, Schiffer R. What makes a good clinical teacher in medicine? A review of the literature. Acad Med. 2008; 83: 45266. [CrossRef] 